\title{
Brief posttrial REM sleep deprivation impairs discrimination learning in rats
}

\author{
CHESTER PEARLMAN and MICHAEL BECKER \\ Department of Psychiatry Research, Boston VA Hospital, Boston, Massachusetts 02130
}

\begin{abstract}
Deprivation of REM sleep (REMD) for about $3 \mathrm{~h}$ immediately after each training session greatly impaired brightness discrimination learning in a Y-maze. REMD beginning $2 \mathrm{~h}$ after training had no effect. Immediate REMD did not impair position learning in this maze. These results suggested that one function of REM sleep is the consolidation or assimilation of information for which the animal is relatively unprepared, as described by Seligman (1970). Consolidation of learning for which the rat is prepared appears to be independent of REM sleep.
\end{abstract}

Attempts to determine the function of REM sleep have generated several hypotheses. Each of these can account for some empirical data but is contradicted by other findings. The idea that REM sleep involves information processing has fewer such inconsistencies than the other theories (Hennevin \& Leconte, 1971). Uncertainty about the role of REM sleep in learning has persisted, however, because some investigators have observed learning impairment with deprivation of REM sleep (REMD), whereas others have not.

We have suggested that survival would require most learning connected with instinctive or habitual behavior to be unaffected by REMD. On the other hand, many activities involving assimilation of unusual information are impaired by REMD. For example, retention of one-trial position learning is unaffected by REMD, whereas latent learning is abolished (Pearlman, 1971). For the wild rat, position learning is a habitual experience. The survival implications of remembering the location of food are evident. With latent learning, however, the indeterminate significance of the prereward maze experience requires a different type of information processing. Similarly, conventional extinction of a barpress habit is little affected by REMD, whereas latent extinction (facilitation of extinction by prior exposure to some aspects of the nonreward condition) is blocked (Pearlman, in press). With respect to aversive learning, Bolles (1970) has distinguished the instinctive character of one-way avoidance from the more unusual shuttlebox situation. One-way avoidance involves only escape from the danger situation, while shuttlebox avoidance requires assimilation of the paradoxical fact that safety lies in returning to a place which was dangerous a moment ago. We have found that retention of one-way avoidance in rats is unimpaired by brief REMD (cf. also Joy \& Prinz. 1969: Miller, Drew. \& Schwartz. 1971). whereas shut tlebox retention is markedly impaired (Leconte \& Hennevin, 1972: Pearlman \& Greenberg. 1973). This distinction between REM-independent and REM-dependent learning can be related to the prepared-unprepared learning continuum proposed by Seligman (1970). Habits for which the rat is prepared are quickly learned (position, one-way avoidance) and are REM-independent. Unprepared learning takes longer (latent learning, shuttlebox avoidance) and involves REM sleep.

The clarity of this distinction between REM-independent and REM-dependent learning in rats has been obscured by other data. For example, with more disruptive treatments, like 3 full days of REMD followed by ECS, retention of one-way avoidance is impaired (Wolfowitz \& Holdstock, 1971). Four days of REMD even impaired acquisition of this task (Hartmann \& Stern, 1972). On the other hand, established learning is unaffected by such treatments. Sloan (1972) found no retention impairment of a previously learned complex maze after 26 days of REMD. Holdstock and Verschoor (1973) found no impairment of prior T-maze learning with 4 days of REMD even though the animals were tested before recovery from REMD. Conflicting data from studies of mice and cats have further complicated the situation [see discussion by Holdstock \& Verschoor (1973)]

The specific relationship between REM sleep and learning is more apparent from EEG studies after training. Leconte, Hennevin, and Bloch (1973) showed that while rats were learning shuttlebox avoidance, REM sleep was significantly increased during the first hour of sleep after each session (within $3 \mathrm{~h}$ after training). Animals who failed to learn the avoidance response and those whose performance had reached a plateau after a few days of training did not show this increase. Lucero (1969) reported similar findings after complex maze training. These data suggested a critical period for the influence of REM sleep on assimilation or consolidation of this information. Thus, REM-dependent learning should be impaired by REMD limited to these critical $3 \mathrm{~h}$ after training. REMD. of similar duration, beginning after the critical period should have no effect. This prediction was confirmed for shuttlebox avoidance by Pearlman and Greenberg (1973). The delayed REMD controls indicated conclusively that REMD impaired memory rather than performance. The same design was used in the present study.

We sought an appetitive situation which would encompass both parts of the prepared-unprepared learning continuum, analogous to one-way and shuttlebox avoidance. A Y-maze. which permits study of 
Table 1

Mean Correct Responses on 10th Day of Discrimination Training (Ranges in Parentheses, $N=10$ )

\begin{tabular}{cll}
\hline Group & \multicolumn{1}{c}{ Condition } & Performance \\
\hline 1 & Lndisturbed Sleep & $16.9^{*}(15-19)$ \\
2 & Saline Injection, Undisturbed Sleep & $17.7^{*}(15-20)$ \\
3 & Immediate Pedestal REMD & $10.5(7-15)$ \\
4 & Immediate Drug REMD & $11.7(9-14)$ \\
5 & Delayed Pedestal REMD & $17.0^{*}(14-20)$ \\
6 & Delayed Drug REMD & $17.9^{*}(14-20)$ \\
\hline
\end{tabular}

*Differs from Groups 3 and $4(p<.001)$

both position learning and brightness discrimination, seemed suitable. Position learning occurs quickly in this situation, but discrimination of a relatively small difference in illumination is difficult. In solving such a discrimination problem, rats generally first adopt a position preference, which keeps performance near chance level, but finally abandon this preference for the more unusual discrimination condition, which leads to rapid improvement (Krechevsky, 1932). Thus, while we expected the position habit to be REM-independent, we wondered if brief posttrial REMD would impair the shift to the discrimination condition.

Pilot work showed that some rats given 20 trials per day on brightness discrimination in a Y-maze made $80 \%$ correct responses after 7 days. Almost all had reached this criterion after 12 days. In contrast, rats having REMD for $3 \mathrm{~h}$ immediately after each session performed much worse. None reached the $80 \%$ criterion in less than 13 days, and some still had not reached it after 20 days. The learning curve of the REMD rats showed the slow improvement characteristic of the terminal phase of sequential maze training rather than the burst of improvement which follows adoption of the discrimination condition. This finding implied impaired ability to assimilate the fact that brightness was a better predictor of reward than position.

The present study replicated the pilot finding with the addition of another method of REMD and control groups having REMD beginning after the critical posttrial period. We also studied the effect of REMD on position learning in this maze.

\section{METHOD}

\section{Subjects}

The Ss were 90 Wistar CD rats, about 4 months old.

\section{Apparatus}

The apparatus was a gray $Y$-maze with plywood sides, $13 \mathrm{~cm}$ high, and wire mesh roof and floor. It consisted of a startbox, 18 $\mathrm{x} 14 \mathrm{~cm}$, a choice chamber, $23 \times 14 \mathrm{~cm}$, and two goalboxes, $28 \mathrm{x}$ $14 \mathrm{~cm}$, all of which were separated by hand-operated guillotine doors. The end wall of each goalbox was a smoked glass plate with a $7.5-\mathrm{W}$ bulb behind it.

\section{Procedure}

Animals were reduced to about $80 \%$ of their normal weight. They were then habituated to the maze by exploration for $1 / 2 \mathrm{~h}$ per day for 5 days. Wet mash was available in each goalbox.

For the discrimination procedure, six groups of 10 animals had 20 trials per day. Training sessions were conducted 4 days a week so that 10 sessions were completed in 15 days. The glass plate in the rewarded box was lighted and that in the other box was dark. The light condition was switched in the following order: RLRRLRLLRRLRLLRLLRRL. The animals were allowed about $5 \mathrm{sec}$ to eat following a correct response and were detained in the nonrewarded goalbox for about $5 \mathrm{sec}$ following an incorrect response. Intertrial interval was about $1 \mathrm{~min}$.

After each training session, two groups had undisturbed sleep, one of which received saline injection, two had immediate REMD by pedestal and drug methods, and two had REMD beginning $2 \mathrm{~h}$ after the session. Group 1 had undisturbed sleep. Group 2 received IP injection of saline about $5 \mathrm{~min}$ after training followed by undisturbed sleep. Group 3 had REMD immediately by being placed on pedestals, $7 \mathrm{~cm}$ in diam, surrounded by water for $2 \mathrm{~h}$ beginning $5 \mathrm{~min}$ after training (cf. Pearlman \& Greenberg, 1973). Group 4 had immediate REMD by IP injection, $5 \mathrm{~min}$ after training, of imipramine $5 \mathrm{mg} / \mathrm{kg}$ or chlordiazepoxide $2 \mathrm{mg} / \mathrm{kg}$ on alternate days. Group 5 rested in home cages for $2 \mathrm{~h}$ and then spent $2 \mathrm{~h}$ on pedestals. Group 6 rested for $2 \mathrm{~h}$ and then received the same drug regimen as Group 4. None of the REMD animals showed the weight loss and hyperactivity caused by more prolonged pedestal REMD. The alternate day drug regimen avoided tachyphylaxis of the imipramine effect and toxicity due to the slow excretion of chlordiazepoxide.

For the position learning procedure, the remaining 30 animals were divided into three groups of 10 . Half of each group had the right goalbox rewarded and the other half had the left box rewarded. Otherwise, the training was identical to the discrimination procedure. After each training session, one group had undisturbed sleep, one group had immediate pedestal REMD for $2 \mathrm{~h}$, and one group had immediate REMD by the previously described drug regimen. Only three sessions were conducted because all animals had reached criterion.

EEG recordings of other animals showed that these REMD procedures were reasonably specific. Both pedestal and drug procedures produced about $3-4 \mathrm{~h}$ of REMD with no significant alteration of amount of REM sleep per $24 \mathrm{~h}$. Pedestal animals had almost no sleep while on the pedestal, but non-REM (NREM) sleep of the drug animals during the first $3 \mathrm{~h}$ after injection did not differ from that of uninjected animals. Saline injection also did not affect NREM sleep but delayed the onsetof Stage REM for about $90 \mathrm{~min}$. This delay decreased with repeated injection. By $3 \mathrm{~h}$ after injection, however, the total amount of REM sleep was similar to that of uninjected animals. Thus, there was no significant REMD during the hypothetical critical period.

\section{RESULTS}

Ten days of training with the discrimination procedure resulted in highly significant separation between experimental and control groups. This difference became apparent after 6 days and reached significance $(p<.05)$ after 8 days. Correct responses on the 10th day are shown in Table 1. The undisturbed sleep and delayed REMD groups showed about the same performance. Only one animal in each group made less than $80 \%$ correct responses. None of the immediate REMD animals had attained the $80 \%$ criterion. Most of 
them showed consistent position responses. Comparisons among all groups by the $U$ test showed that on the 10th day, both immediate REMD groups performed significantly poorer than the undisturbed sleep and delayed REMD groups $(\mathrm{p}<.001)$.

With the position learning procedure, all animals had attained the $80 \%$ criterion after 3 days. Results for the third day are shown in Table 2. There were no significant differences among the groups on any day.

\section{DISCUSSION}

REMD for about $3 \mathrm{~h}$ immediately after each learning session greatly impaired brightness discrimination learning. A similar period of REMD beginning $2 \mathrm{~h}$ after training had no effect. Immediate REMD did not impair position learning, however.

Since all REMD procedures have nonspecific effects, one might wonder whether these findings resulted from REMD or something else. Critics have often raised the possibility of impairment of sensory or motivational mechanisms and suggested that the poorer learning resulted from a performance rather than a memory deficit. In the present situation, however, these nonspecific concomitants of the REMD procedures would have had about the same influence on both delayed and immediate REMD animals. One might postulate retroactive interference due to stress or NREM sleep loss during the critical period caused by the pedestal procedure, but the drug REMD regimen involved no stress or NREM sleep loss. Similarly, one might postulate retroactive interference due to the drugs, but the pedestal animals received no drugs. Chlordiazepoxide and imipramine are, in general, pharmacologic antagonists. REMD is the most significant effect shared by either drug with the pedestal procedure. Thus, the parsimonious conclusion is that immediate REMD was the variable responsible for retarded discrimination learning.

The absence of impairment with delayed REMD confirms the suggestion of Leconte, Hennevin, and Bloch (1973) that the elevation of Stage REM during the first hour of sleep after training is critical for learning. The results with saline are consistent with the finding of Leconte and Hennevin (1972) that the onset of REM sleep can be delayed for about an hour after training with no deleterious effect.

Some question remains whether the observed impairment resulted from interference with a consolidation mechanism or from an aversive effect of REMD. The effects of punishing shock in this learning situation have been extensively studied. This work has shown either improved $p \in$ rformance or no effect due to the shock (Fowler \& Wischner, 1969), but these data may not be applicable to the present study. In general, the delay of punishment gradient with shock becomes
Table 2

Mean Correct Responses on 3rd Day of Position Training (Ranges in Parentheses, $\mathbf{N}=10$ )

\begin{tabular}{clcc}
\hline Group & \multicolumn{1}{c}{ Condition } & \multicolumn{2}{c}{ Performance } \\
\hline 1 & Undisturbed Sleep & 19.8 & $(19-20)$ \\
2 & Immediate Fedestal REMD & 19.4 & $(19-20)$ \\
3 & Immediate Drug REMD & 18.8 & $(16-20)$ \\
\hline
\end{tabular}

asymptotic by $30 \mathrm{sec}$ after the learning irial (Myer, 1970). Thus, the shock data are probably not relevant to a situation where the aversive treatment began several minutes after training. On the other hand, the different effects of immediate and delayed REMD might be analogous to the greater degree of conditioned taste aversion produced by $\mathrm{LiCl}$ administration $1 \mathrm{~h}$ after exposure to the $\mathrm{CS}$ compared to $4 \mathrm{~h}$ after exposure (Nachman, 1970). LiCl produces severe gastrointestinal disturbance but otherwise resembles brief REMD more than amnesic agents like ECS, with which aversive effects are also found (Spevack \& Suboski, 1969). Since taste aversions are usually established in one trial, a REMD-induced aversion to the food reward should have produced impairment of the position learning task. Due to the relatively mild aversiveness of brief REMD and the familiarity of the mash reward, however, several days might be necessary for development of a taste aversion. This possibility seemed unlikely because the immediate REMD animals never stopped eating after correct responses on the discrimination task. Thus, any aversive effect of brief REMD seemed unimportant compared to the effect upon consolidation.

These findings are consistent with the conclusion that learning for which the rat is prepared (position) is REM-independent, whereas unprepared learning (brightness discrimination) is REM-dependent. This distinction may facilitate interpretation of REMD experiments in humans. Tasks involving familiar (prepared) cognitive functions, like paired-associate learning, are unaffected by REMD, whereas adaptation to threatening (unprepared) situations is impaired by REMD (Greenberg. Pillard, \& Pearlman, 1972).

\section{REFERENCES}

Bolles, R. C. Species-specific defense reactions and avoidance learning. Psychological Review, 1970, 77, 32-48.

Fowler. H., \& Wischner, G. J. The varied functions of punishment in discrimination learning. In B. A. Campbell and R. M. Church (Eds.), Punishment and aversive behavior. New York: Appleton-Century-Crofts, 1969. Pp. 375-420.

Greenberg, R., Pillard. R., \& Pearlman, C. The effect of dream (stage REM) deprivation on adaptation to stress. Psychosomatic . Medicine, 1972. 34, 257-262.

Hartmann, E.. \& Stern, W. C. Desynchronized sleep deprivation: Learning deficit and its reversal by increased catecholamines. Phýsiology \& Behavior, 1972. 8. 585-587.

Hennevin, E., \& Leconte, P. La fonction du sommeil paradoxal: 
Faits et hỵpothèses. Année Psychologique, 1971. 2. 489-519. Holdstock. T. L.. \& Verschoor, G. J. Retention of maze learning following paradoxical sleep deprivation in rats. Physiological Psychology. 1973. 1, 29-33.

Joy, R. M.. \& Prinz, P. N. The effect of sleep-altering environments upon the acquisition and retention of a conditioned avoidance response. Physiology \& Behavior, 1969. 4. 809-814.

Krechevsky, I. "Hypotheses" in rats. Psychological Review, 1932, 39. 516-532.

Leconte, P., \& Hennevin, E. Sommeil paradoxal et mémorisation: Effet du délai d'endormissement chez le rat. Journal de Physiologie (Paris), 1972, 65, 255 A-256A.

Leconte. P.. Hennevin, E., \& Bloch. V. Analyse des effets d'un apprentissage et de son niveau d'acquisition sur le sommeil paradoxal consécutif. Brain Research, 1973, 46, 367-379.

Lucero. M. Lengthening of REM sleep duration consecutive to learning in the rat. Brain Research, 1970, 20, 319-322.

Miller. L.. Drew. W. G., \& Schwartz, I. Effect of REM sleep deprivation on retention of a one-trial passive avoidance response. Perceptual \& Motor Skills, 1971, 33, 118.

Iyer, J. S. Some effects of noncontingent aversive stimulation. In F. Brush (Ed.), Aversive conditioning and learning. New York: Academic Press, 1970. Pp. 469-536.
Nachman, M. Learned taste and temperature aversions due to lithium chloride sickness after temporal delays. Journal of Comparative \& Physiological Psychology, 1970, 73, 22-30.

Pearlman, C. Latent learning impaired by REM sleep deprivation. Psychonomic Science, 1971, 25, 135-136.

Pearlman, C. REM sleep deprivation impairs latent extinction in rats. Physiology \& Behavior, in press.

Pearlman, C., \& Greenberg, R. Posttrial REM sleep: A critical period for consolidation of shuttlebox avoidance. Animal Learning \& Behavior, 1973, 1. 49-51.

Seligman, M. E. P. On the generality of the laws of learning. Psychological Review, 1970, 77, 406-418.

Sloan, M. A. The effects of deprivation of rapid eye movement (REM) sleep on maze learning and aggression in the albino rat. Journal of Psy'chiatric Research, 1972, 9, 101-111.

Spevack, A., \& Suboski, M. D. Retrograde effects of electroconvulsive shock on learned responses. Psychological Bulletin, 1969, 72, 66-76.

Wolfowitz, B. E., \& Holdstock, T. L. Paradoxical sleep deprivation and memory in rats. Communications in Behavioral Biology, 1971, 6, 281-284.

(Received for publication August 27, 1973; accepted September 10,1973.) 